\title{
Immunohistochemical expression of p21 in normal tissues of salivary gland, pleomorphic adenoma and carcinoma ex pleomorphic adenoma- (undifferentiated and adenocarcinoma types)
}

\author{
Bassel Tarakji ${ }^{1}$, Mohammad Z Nassani ${ }^{2}$ \\ ${ }^{1}$ Head of Department of Oral Pathology, Faculty of Dentistry, Aleppo University, Aleppo, Syria \\ ${ }^{2}$ Lecturer, Faculty of Dentistry, Aleppo University, Aleppo, Syria
}

Correspondence:

Department of Oral Pathology

Faculty of Dentistry, Aleppo University

Aleppo, Syria

denpol@yahoo.co.uk

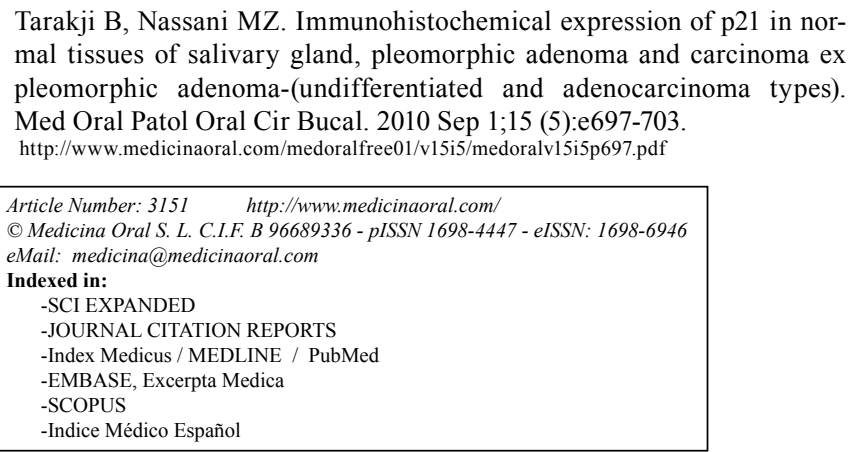

\begin{abstract}
Objective: Our study aimed to characterize alteration in the immunohistochemical expression of p21 in normal tissue of the salivary gland surrounding pleomorphic adenoma, the tumor cells of pleomorphic adenomas, and carcinoma arising in pleomorphic adenoma.

Study design: A selected series of 29 cases of pleomorphic adenomas, and 27 cases of carcinoma ex-pleomorphic adenoma (undifferentiated and adenocarcinoma types) were examined.

Results: The results showed that $\mathrm{p} 21$ expression was negative in the most components of normal tissue of the salivary gland surrounding pleomorphic adenoma, 24 cases out of 29 of the non tumour duct cells (82.8\%), and $28(96.6 \%)$ cases out of 29 of the acinar cells shows negative p21 expression. P21 expression in pleomorphic adenomas shows that 2 cases out of $29(6.9 \%)$ strongly expressed in the duct cells. p21 was strongly expressed in carcinoma cells in $9(33.3 \%)$ cases out of 27 .

Conclusion: Our data suggest that the strong nuclear staining as an indicator for altered p21, then the alteration of p21 expression would increase from pleomorphic adenoma to carcinoma arising in pleomorphic adenomas $(6.9 \%$ versus $33.3 \%$ ).
\end{abstract}

Key words: p21 expression, pleomorphic salivary adenoma, carcinoma ex pleomorphic adenoma. 


\section{Introduction}

p21 is a cell cycle regulatory protein encoded by the p 21 WAF 1 gene which is located on chromosome 6p21.2, (1-2). It believed that the inhibitory effects on cell division by $\mathrm{p} 21$ are related to cancerous change of normal cells, regulation, cell differentiation and induction of apoptosis involving p53 and $\mathrm{Rb}$ (3). P21 plays an important role in arresting the cell cycle. Loss of function of p21 may favour tumour growth. Pleomorphic salivary adenoma (PSA), the most frequent tumour in salivary glands, can undergo malignant transformation. Carcinoma ex pleomorphic adenoma (CXPA) is more frequent in the 5-6th decades of life (4-5). It has been suggested that a carcinoma may develop within a recurrent PSA or when it remains untreated over an extended period of time (6-7). Despite the recognized clinical importance of CXPA, little is known about its biology, therefore the diagnosis of CXPA is a challenge for pathologists. The purpose of this study was to determine, with the use of immunohistochemistry, to characterize alteration in the immunohistochemical expression of p21 in normal tissue of the salivary gland surrounding pleomorphic adenoma, the tumor cells of pleomorphic adenomas, and carcinoma arising in pleomorphic adenoma.

\section{Materials and Methods}

\section{Case selection}

A selected series tissue 29 cases of pleomorphic adenomas, and 27 cases of carcinoma ex-pleomorphic adenoma were retrieved from the archive of the oral pathology departments in the North West region of England (Table 1). Normal tissue of the salivary gland surrounding the

Table 1. Clinical data of 29 pleomorphic adenomas cases (PA) and 27 carcinomas ex-pleomorphic adenomas cases (CXPA).

\begin{tabular}{|c|c|c|c|c|c|c|c|c|c|}
\hline $\begin{array}{c}\text { P A } \\
\text { Cases }\end{array}$ & Age & Gender & Gland type & $\begin{array}{l}\text { CXPA } \\
\text { Cases }\end{array}$ & Age & Gender & Gland & $\begin{array}{l}\text { Histological sub- } \\
\text { type }\end{array}$ & $\begin{array}{l}\text { Metastasis to } \\
\text { lymph nodes* }\end{array}$ \\
\hline 1 & 87 & $\mathrm{~F}$ & Parotid gland & 1 & 77 & $\mathrm{~F}$ & Parotid & Adenocarcinoma & Yes \\
\hline 2 & 52 & M & Parotid gland & 2 & 28 & $\mathrm{M}$ & Parotid & Adenocarcinoma & No \\
\hline 3 & 63 & $\mathrm{M}$ & Parotid gland & 3 & 78 & M & Submandibular & Undifferentiated & Yes \\
\hline 4 & 48 & $\mathrm{~F}$ & Parotid gland & 4 & 45 & $\mathrm{M}$ & Parotid & Undifferentiated & Yes \\
\hline 5 & 76 & $\mathrm{~F}$ & Parotid gland & 5 & 76 & $\mathrm{~F}$ & Parotid & Undifferentiated & No \\
\hline 6 & 47 & M & Parotid gland & 6 & 82 & $\mathrm{~F}$ & Parotid & Undifferentiated & No \\
\hline 7 & 62 & $\mathrm{~F}$ & Parotid gland & 7 & 71 & $\mathrm{M}$ & Parotid & Adenocarcinoma & No \\
\hline 8 & 33 & $\mathrm{M}$ & Parotid gland & 8 & 67 & $\mathrm{M}$ & Submandibular & Undifferentiated & Yes \\
\hline 9 & 49 & $\mathrm{~F}$ & Parotid gland & 9 & 63 & $\mathrm{M}$ & Submandibular & Undifferentiated & Yes \\
\hline 10 & 45 & M & Parotid gland & 10 & 55 & M & Submandibular & Undifferentiated & Yes \\
\hline 11 & 63 & $\mathrm{~F}$ & Parotid gland & 11 & 73 & M & Parotid & Undifferentiated & Yes \\
\hline 12 & 53 & $\mathrm{~F}$ & Parotid gland & 12 & 71 & M & Parotid & Undifferentiated & No \\
\hline 13 & 27 & $\mathrm{~F}$ & Parotid gland & 13 & 64 & $\mathrm{M}$ & Parotid & Undifferentiated & Yes \\
\hline 14 & 59 & $\mathrm{~F}$ & Parotid gland & 14 & 60 & $\mathrm{~F}$ & Parotid & Undifferentiated & Yes \\
\hline 15 & 33 & $\mathrm{~F}$ & Parotid gland & 15 & 49 & $\mathrm{~F}$ & Submandibular & Undifferentiated & No \\
\hline 16 & 55 & $\mathrm{~F}$ & Parotid gland & 16 & 39 & $\mathrm{~F}$ & Parotid & Undifferentiated & Yes \\
\hline 17 & 26 & $\mathrm{~F}$ & Parotid gland & 17 & 56 & $\mathrm{M}$ & Parotid & Undifferentiated & No \\
\hline 18 & 65 & $\mathrm{~F}$ & Parotid gland & 18 & 45 & $\mathrm{~F}$ & Parotid & Undifferentiated & Yes \\
\hline 19 & 40 & M & Parotid gland & 19 & 57 & $\mathrm{M}$ & Parotid & Undifferentiated & Yes \\
\hline 20 & 57 & $\mathrm{M}$ & Parotid gland & 20 & 66 & $\mathrm{~F}$ & Parotid & Undifferentiated & No \\
\hline 21 & 34 & M & Parotid gland & 21 & 86 & $\mathrm{~F}$ & Submandibular & Undifferentiated & Yes \\
\hline 22 & 74 & $\mathrm{~F}$ & Parotid gland & 22 & 17 & $\mathrm{~F}$ & Parotid & Undifferentiated & No \\
\hline 23 & 67 & $\mathrm{~F}$ & Parotid gland & 23 & 78 & $\mathrm{M}$ & Submandibular & Undifferentiated & Yes \\
\hline 24 & 32 & $\mathrm{M}$ & Parotid gland & 24 & 26 & $\mathrm{M}$ & Parotid & Undifferentiated & No \\
\hline 25 & 31 & M & Parotid gland & 25 & 31 & $\mathrm{~F}$ & Parotid & Undifferentiated & No \\
\hline 26 & 62 & $\mathrm{~F}$ & Parotid gland & 26 & 71 & M & Parotid & Undifferentiated & No \\
\hline 27 & 76 & $\mathrm{~F}$ & Parotid gland & 27 & 71 & $\mathrm{M}$ & Parotid & Undifferentiated & No \\
\hline 28 & 21 & $\mathrm{~F}$ & Parotid gland & & & & & & \\
\hline 29 & 61 & $\mathrm{~F}$ & Parotid gland & & & & & & \\
\hline
\end{tabular}

F: female M: male, * Metastasis to lymph nodes at the time of tumour resection. 
tumour was used as a control in 29 cases of pleomorphic adenoma. The immunohistochemical expression of antibodies against $\mathrm{p} 21$ was examined in the selected cases. The proposed criteria for defining carcinoma ex-pleomorphic adenoma by Nagao et al. (8) were used to select and reclassify our cases of carcinoma ex-pleomorphic adenoma.

The use of strict pathological criteria may underestimate the frequency of carcinoma ex pleomorphic adenoma because the malignant cells in some cases may obliterate the original pleomorphic adenoma.

Inclusion criteria for carcinoma ex-pleomorphic adenoma:

- Major gland primary lesion (parotid or submandibular)

- Co-existent benign and malignant elements

Benign element can be:

- Pleomorphic adenoma within the tumor mass

- Biopsy proven history of previous PSA (pleomorphic salivary adenoma) indicated that it was in the same location as the subsequent carcinoma.

Malignant elements can be:

- Undifferentiated carcinoma

- Adenocarcinoma

- Multiple patterns of differentiation including undifferentiated or adenocarcinoma patterns

Exclusion criteria for carcinoma ex-pleomorphic adenoma includes any other type of tumor.

All specimens using hematoxylin and eosin slides were reviewed by two pathologists to confirm the histopathological diagnosis and to reclassify the studied cases. The carcinoma cases classified according to the above mentioned criteria as undifferentiated carcinoma or adenocarcinoma. The local NHS Research Ethics Committee provided a favourable ethical opinion (Ref: 02/104).

\section{Immunhistochemistry}

Paraffin-embedded, 4- $\mu \mathrm{m}$-thick tissue sections from all 56 specimens were cut. The sections were deparaffinized in xylene and rehydrated through graded alcohols. Sections were processed used streptavidin-biotin-peroxidase method. Briefly, the endogenous peroxidase was blocked by $3 \%$ hydrogen peroxidase for $5 \mathrm{~min}$ followed by TBS wash. Nonspecific immunoreactivity was blocked by incubation with normal goat serum for 20 minutes. A purified mouse anti-human monoclonal antibody p21 (Pharmingen, San Diego) was diluted to $10 \mu / \mathrm{ml}$ in $20 \mu / \mathrm{ml}$ tris buffer saline containing $0.1 \%$ bovine serum albumin for one hour and fifteen minutes at the room temperature. All sections were washed by TBS for 5 minutes. Sections were incubated with the biotinylated secondary antibody reagent for 30 minutes followed by (TBS) wash for 5 minutes. Slides were incubated with streptavidin and horseradish peroxidase for 30 minutes followed by (TBS) tris buffer saline wash for 5 minutes. Incubate with a prepared chromog- enic substrate solution (Diaminobenizidine) for $15 \mathrm{~min}$ utes. Sections were counterstained with $0.25 \%$ methyl green in distilled water for 5 minutes. Sections were dehydrated and mounted in Depax. Squamous cell carcinoma was used as positive control. Negative control was used only with substitution the primary antibody with TBS (Fig. 1a). The percentage of P21 positive nuclei was semiquantively assessed by two independent observers and scored as: negative (0) no expression of nuclear protein, (1) weak staining $0-25 \%$ of the total cells shows positive staining in the nucleus, (2) moderate staining $>25-75 \%$ of the total cells in the test area show positive nuclear staining, (3) strong staining $>75$ $100 \%$ cells show positive nuclear staining.

Statistical analysis

Cells of the carcinomatous component of the CXPA were always scored. The statistical analysis included the use of descriptive statistics; frequencies proportion and crossed tabulation. Also, statistical analyses, including Mann-Whitney and Wilcoxon's nonparametric tests, were performed on the data. All statistical tests were two-sided and p-values less than 0.05 were considered to be statistically significant.

\section{Results}

p21 expression in the control group (normal tissue) surrounding the pleomorphic adenoma

Of the 29 cases, p21 expression of the non tumour duct cells was negative in $24(82.8 \%)$, and weak in 5 cases $(17.2 \%)$ cases with weak staining. P21 (nuclear staining of the acinar cells) showed negative staining in 28 (96.6\%) cases out of 29, 1 (3.4\%) case expressed weak staining (Fig. 1b). P21 (nuclear staining in stroma) was negative in $29(100 \%)$ cases out of 29.

P21 expression in pleomorphic adenoma components p21 nucleus staining was moderate in tumour duct cells in 13 (44.8\%) cases out of 29 (Fig. 1c), 13 (44.8\%) cases showed weak staining (Fig. 1d), 1 (3.4\%) case negative staining, and 2 cases $(6.9 \%)$ strong staining (Table 2), (Fig. 1e). p21 nuclear staining in myxochondroid tissue was identified in $20(69.0 \%)$ cases with weak staining, $4(13.8 \%)$ cases with moderate staining, and $5(17.2 \%)$ cases with negative staining (Table 2). Also the crosstabulation table showed $\mathrm{p} 21$ expression in tumour duct cells and myxochondroid tissue (Table 2).

Comparison between staining of different components in pleomorphic adenoma and the adjacent tissue around this tumour

Wilcoxon test showed a significant difference ( $\mathrm{p}$ value $<0.001$ ) between $\mathrm{p} 21$ expression in the nuclei of duct cells in normal tissue surrounding the tumour and the tumour area. The non tumour duct cells showed 24 cases with p21 negative staining, whereas there were 5 cases with weak staining but in the tumour duct cells, 1 case showed negative staining, 13 weak staining, 13 moderate 


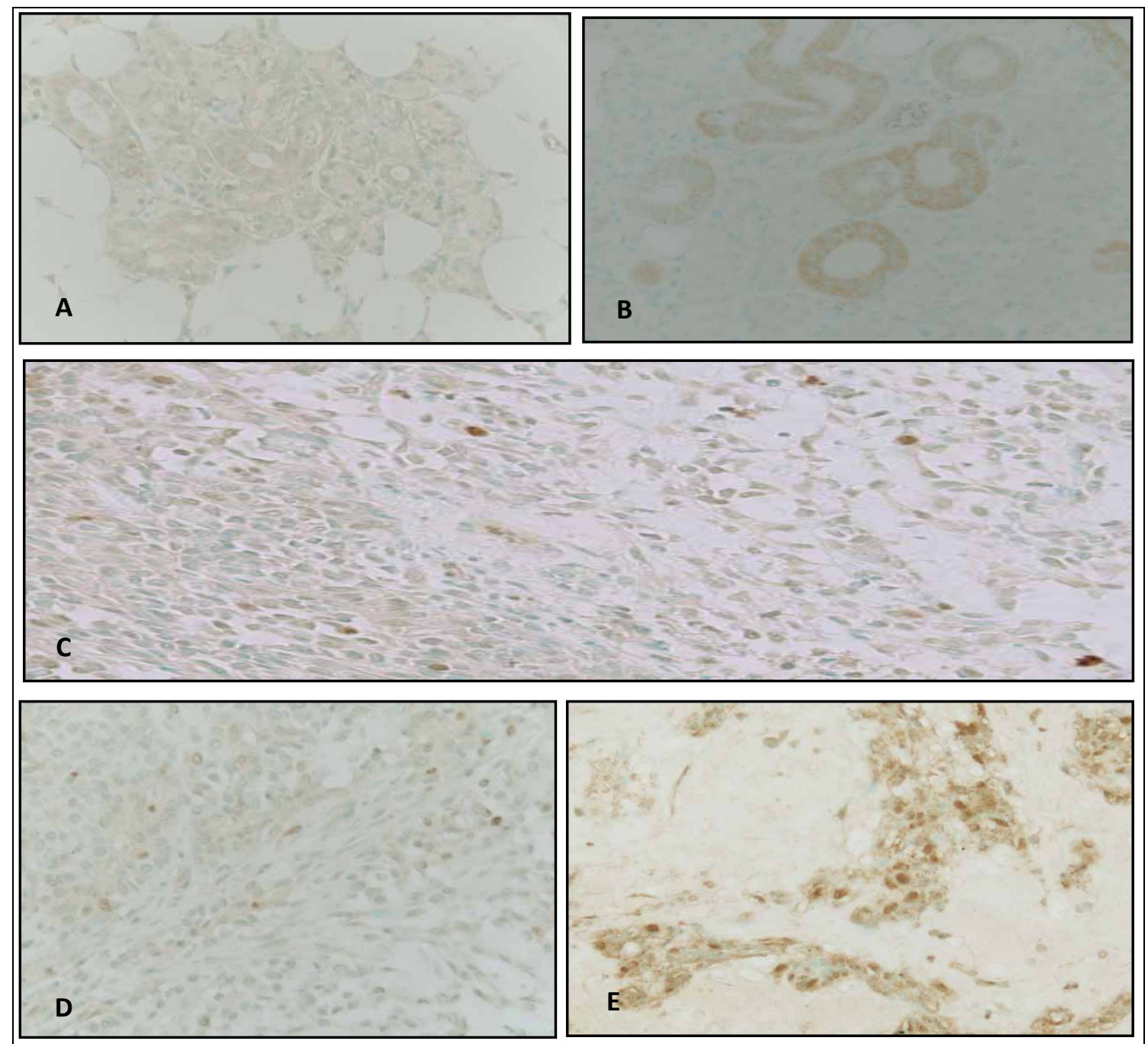

Fig. 1. Showing nuclear staining of p21 in normal tissue of parotid gland and pleomorphic adenoma components (Original magnification $\mathrm{x} 40$ ), A showing p21 negative control, B showing negative nuclear staining of p21 in ductal and acinar cells in parotid gland, C showing moderate nuclear staining of p21 in pleomorphic salivary adenoma, D showing low nuclear staining of p21 in pleomorphic salivary adenoma, E strong nuclear staining of p21 in pleomorphic salivary adenoma.

staining, and 2 cases strong staining. We conclude that there was a greater alteration of p21 expression in the tumour duct cells compared with non tumour duct cells. The Wilcoxon test identified a significant difference $(\mathrm{p}$ value $=0.002$ ) between $\mathrm{p} 21$ expression in the nuclear staining in myxochondroid and tumour duct cells because the tumour duct cells showed negative staining in 1 case, 13 showed weak staining, 13 moderate staining, and 2 strong staining but in the myxochondroid tissue, 5 cases had negative staining, 20 weak staining, and 4 expressed moderate staining (Table 2). This means that the incidence of overexpressed p21 in tumour duct cells was higher than in tumour myxochondroid tissue.

p21 expression in carcinoma arising in pleomorphic adenoma p21 was strongly expressed in carcinoma cells in 9 (33.3\%) cases out of 27 (Fig. 2a). 5 (18.5\%) cases showed moderate staining (. 2b), and $5(18.5 \%)$ cases expressed low staining (Fig. 2c), 8 cases (29.6\%) negative staining. Comparison between p21 expression in pleomorphic adenoma and carcinoma arising in pleomorphic adenoma

The Mann Whitney test showed no significant difference between p21 expression in pleomorphic adenoma (tumour duct cells) and carcinoma arising in PSA ( $p$ value $0.939>0.05$ ). p21 nuclear staining was moderate in tumour duct cells (pleomorphic adenoma) in $13(44.8 \%)$ cases out of $29,13(44.8 \%)$ cases showed weak staining, $1(3.4 \%)$ case negative staining, and 2 cases $(6.9 \%)$ strong staining but $\mathrm{p} 21$ in carcinoma cells 
Table 2. Crosstabulation table shows comparison between p21 expression in myxochondroid tissue and tumour duct cells in pleomorphic adenoma.

\begin{tabular}{|l|c|c|c|c|c|}
\hline & \multicolumn{3}{|c|}{ P21 in duct cells } & \\
\hline & $\begin{array}{c}\text { Negative } \\
\text { Staining }\end{array}$ & $\begin{array}{c}\text { Weak } \\
\text { staining }\end{array}$ & $\begin{array}{c}\text { Moderate } \\
\text { staining }\end{array}$ & $\begin{array}{c}\text { Strong } \\
\text { staining }\end{array}$ & Total \\
\hline P21 expression in Myxochondroid & & & & & \\
Negative staining & 0 & 4 & 1 & 0 & 5 \\
Weak staining & 1 & 7 & 10 & 2 & 20 \\
Moderate staining & 0 & 2 & 2 & 0 & 4 \\
Strong staining & 0 & 0 & 0 & 0 & 0 \\
Total & 1 & 13 & 13 & 2 & 29 \\
\hline
\end{tabular}
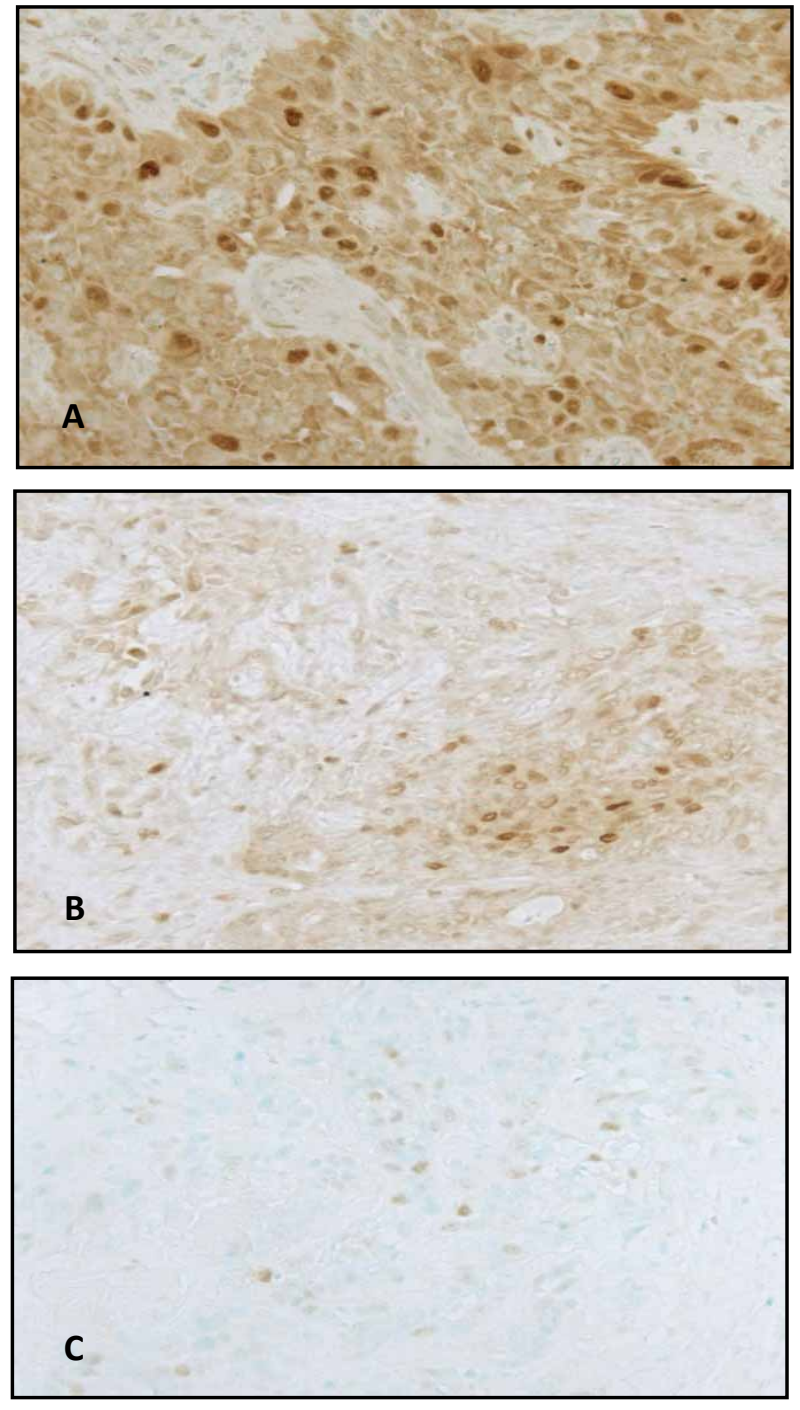

Fig. 2. Showing nuclear staining of p21 in carcinomas ex-pleomorphic adenomas, (Original magnification x40), A showing strong nuclear staining of $\mathrm{p} 21$ in CXPA. B showing moderate nuclear staining of 21 in CXPA, $C$ showing low nuclear staining of p21 in CXPA. showed $9(33,3 \%)$ strong staining, 5 cases moderate staining (18.5\%), 5 cases (18.5\%) low staining, 8 cases (29.6\%) negative staining. These results showed that mutation of p21 increased from pleomorphic adenoma to carcinoma arising in pleomorphic adenoma.

\section{Discussion}

p21 belongs to a class of tumour suppressors including p16 and p27, which control progression through the cell cycle by inhibiting the activity of cyclin-cdk complexes.

No study has been published regarding p21 expression in salivary glands and particularly in carcinoma arising in pleomorphic adenoma.

P21 and normal tissue of salivary glands

In the normal salivary glands (control group) p21 was negative in the non tumour duct cells or the acini. These results are consistent with Rey et al. (9) who studied p21 expression in breast cancer. The normal ducts and acinar cells did not express p21 and the same negative p21 nuclear staining was observed in the five non-neoplastic cases.

Clasen et al. (10) analysed the expression of p21 in urothelial carcinoma. Their results revealed that no p21 was expressed in normal mucosa. Jung et al. (11) analysed the expression of $\mathrm{p} 21$ in normal and reactive brain in gliomas of various malignancy grades. Immunhistochemical assay showed that the p21 detected in normal and reactive brain tissue with at very low expression.

Expression of p21 in the tumour duct cells and myxochondroid tissue in pleomorphic adenomas

Wilcoxon test showed a significant difference between p21 expression of the nuclear staining in myxochondroid and tumour duct cells, ( $p$ value $<0.001$ ).

p21 expression in pleomorphic adenoma showed that the incidence of aberrant expression of this protein was higher in tumour duct cells than in myxochondroid tissue. Although p21 showed alteration in expression in 
myxochondroid tissue, there is evidence that cells in myxochondroid tissue show low levels of proliferation Zhu et al. (12).

$P 21$, pleomorphic adenoma, and carcinoma arising in pleomorphic adenoma

It was considered that $\mathrm{p} 21$ strong and moderate nuclear staining was positive, and an indicator for altered p21 in pleomorphic adenoma and carcinoma arising in PSA. Low and negative nuclear staining was classified as negative, and indicated wild type (non altered p21). P21 showed positive nuclear staining (moderate and strong) in 15 (51.7\%) out of 29 cases in tumour duct cells of pleomorphic adenoma. In carcinoma arising in pleomorphic adenoma, p21 staining was positive in $14(51.8 \%)$ cases out of 27.

De lima et al. (13) reported that no expression of p21 was found in adenoid cystic carcinomas. Marques et al. (14) reported that p21 expression was considered absent in pleomorphic adenomas and myoepitheliomas. Harada et al. (3) reported that p21 expression was increased in non small lung carcinoma, hepato cellular carcinoma, and head and neck cancers. Rey et al. (9) studied p21 expression in breast cancer. Expression of p21 (using anti p21 clone, EA10 from Oncogene Science) was observed in preinvasive lesions, and in infiltrating carcinomas (57\%). P21 expression was associated with high histological grade (II-III). P21 positivity correlated with increased proliferation. Jung et al. (11) used an immunohistochemical assay and demonstrated that p21 (using $\mathrm{mAb}$ obtained from Oncogene Science) was positive in both astrocytoma (low grade) and glioblastoma (high grade) in the tested paraffin blocks of brain tumours. Ogawa et al. (15) observed that loss of p21 expression correlated with disease progression in gastric carcinoma. Brunotto et al. (16) observed that the Ck14, p53, p21 and Bcl-2 proteins were found modified in the leukoplakia, oral lichen planus and squamous cell carcinoma.

P21 strong nuclear staining as a strong indicator for altered $p 21$

Using strong nuclear staining as a indicator for altered $\mathrm{p} 21$, the proportion of $\mathrm{p} 21$ positive tissues would be 6.9 $\%$ in pleomorphic adenoma cases. In my sample, only 2 cases out of 29 showed strong positive staining in the tumour duct cells of pleomorphic adenomas. In carcinoma arising in PSA, 9 (33.3\%) cases out of 27 showed positive strong staining.

The interpretation of the variations in the detection of p21 staining

This differences may have resulted from the following reasons:

1. The use of different antibodies

2. Different classifications e.g $(0=$ negative staining, $1=$ low, $2=$ moderate, $3=$ strong or $0-3=$ negative and $4=$ positive or $0-2=$ negative and $3-4=$ positive or negative and positive staining).
3. Fixation times and concentrations of antibodies

4. The sensitivity of the technique used

Mutation is usually increased as cells progress from benign tumour to carcinoma. It was surprising that the results showed that the proportion of altered p21 in pleomorphic adenomas was comparable with in carcinoma cases, 15 (51.7\%) out of 29 cases versus $14(51.8 \%)$ cases out of 27, after combining moderate and strong staining together, and negative and low staining together. If only strong positive staining (p21) was used as indicator for the alteration in the expression of tumour suppressor protein, then alteration in expression of $\mathrm{p} 21$ was detected in two cases out of $29(6.9 \%)$ in pleomorphic adenoma and increased in carcinoma arising in pleomorphic adenoma in nine cases out of 27 (33.3\%).

Immunostaining technique is an easy method to carry out but the assessment of the positive or negative nuclear staining cells is controversial. Many authors used different criteria so the results cannot be compared. In the present study, the use of negative and positive staining for the assessment of staining avoided any confusion in the interpretation of the results. Ideally the immunostaining technique is used only combined with another technique e.g (Ploymerase Chain Reaction, Western Blotting) to detect and confirm existence of a mutation. Many studies used criteria such as negative, low, moderate, and strong staining. This study comprised 29 cases of pleomorphic adenoma and 27 cases of carcinoma ex pleomorphic adenoma, although the sample size is limited but it is bigger compared to other published studies. We have concluded that the alteration of $\mathrm{p} 21$ expression has increased from pleomorphic adenoma to carcinoma arising in pleomorphic adenoma depending on use the p21 strong nuclear staining as a strong indicator for altered $\mathrm{p} 21$.

\section{References}

1. El-Deiry WS, Tokino T, Velculescu VE, Levy DB, Parsons R, Trent JM, et al. WAF1, a potential mediator of p53 tumor suppression. Cell. 1993;75:817-25.

2. El-Deiry WS, Harper JW, O’Connor PM, Velculescu VE, Canman CE, Jackman J, et al. WAF1/CIP1 is induced in p53-mediated G1 arrest and apoptosis. Cancer Res. 1994;54:1169-74.

3. Harada K, Ogden GR. An overview of the cell cycle arrest protein, p21(WAF1). Oral Oncol. 2000;36:3-7.

4. Horn-Ross PL, West DW, Brown SR. Recent trends in the incidence of salivary gland cancer. Int J Epidemiol. 1991;20:628-33.

5. Olsen KD, Lewis JE. Carcinoma ex pleomorphic adenoma: a clinicopathologic review. Head Neck. 2001;23:705-12.

6. Eneroth CM, Zetterberg A. Malignancy in pleomorphic adenoma. A clinical and microspectrophotometric study. Acta Otolaryngol. 1974;77:426-32.

7. Gnepp DR. Malignant mixed tumors of the salivary glands: a review. Pathol Annu. 1993;28 Pt 1:279-328.

8. Nagao K, Matsuzaki O, Saiga H, Sugano I, Shigematsu H, Kaneko $\mathrm{T}$, et al. Histopathologic studies on carcinoma in pleomorphic adenoma of the parotid gland. Cancer. 1981;48:113-21.

9. Rey MJ, Fernández PL, Jares P, Muñoz M, Nadal A, Peiró N, et al. $\mathrm{P} 21 \mathrm{WAF} 1 / \mathrm{Cip} 1$ is associated with cyclin D1CCND1 expression and 
tubular differentiation but is independent of $\mathrm{p} 53$ overexpression in human breast carcinoma. J Pathol. 1998;184:265-71.

10. Clasen S, Schulz WA, Gerharz CD, Grimm MO, Christoph F, Schmitz-Dräger BJ. Frequent and heterogeneous expression of cyclin-dependent kinase inhibitor WAF1/p21 protein and mRNA in urothelial carcinoma. Br J Cancer. 1998;77:515-21.

11. Jung JM, Bruner JM, Ruan S, Langford LA, Kyritsis AP, Kobayashi $\mathrm{T}$, et al. Increased levels of p21WAF1/Cip1 in human brain tumors. Oncogene. 1995;11:2021-8.

12. Zhu Q, Tipoe GL, White FH. Proliferative activity as detected by immunostaining with $\mathrm{Ki}-67$ and proliferating cell nuclear antigen in benign and malignant epithelial lesions of the human parotid gland. Anal Quant Cytol Histol. 1999;21:336-42.

13. De Lima Mde D, Marques YM, Alves Sde M Jr, Freitas VM, Soares FA, de Araújo VC, et al. MDM2, P53, P21WAF1 and pAKT protein levels in genesis and behaviour of adenoid cystic carcinoma. Cancer Epidemiol. 2009;33:142-6.

14. Marques YM, de Lima Mde D, de Melo Alves Sde M Jr, Soares FA, de Araújo VC, Pinto Ddos S Jr, et al. Mdm2, p53, p21 and pAKT protein pathways in benign neoplasms of the salivary gland. Oral Oncol. 2008;44:903-8.

15. Ogawa M, Maeda K, Onoda N, Chung YS, Sowa M. Loss of p21WAF1/CIP1 expression correlates with disease progression in gastric carcinoma. Br J Cancer. 1997;75:1617-20.

16. Brunotto M, Zárate AM, Cismondi A, Fernández Mdel C, Noher de Halac RI. Valuation of exfoliative cytology as prediction factor in oral mucosa lesions. Med Oral Patol Oral Cir Bucal. 2005;10 Suppl 2:E92-102. 